\title{
Design e transgressão
}

\section{RESUMO}

O campo do design da comunicação gráfica está passando por importantes transformações, decorrentes do crescente descrétido com que se defrontam seus cânones modernistas, herdados da Bauhaus e da Escola Suíça, e consolidados posteriormente pela corrente do International Style. As criações de designers vistos como pós-modernos (como as de April Greiman, Neville Brody e David Carson, só para citar os mais conhecidos profissionais do cenário atual) rejeitam os preceitos apriorísticos de legibilidade e funcionalidade daqueles movimentos, cultivando a intuição, a hibridação, a desordem, a improvisação e todo tipo de impertinências gráficas (fragmentos, 'sujeiras', 'ruídos', desfocalizações). Procurando entender o porquê desse "retorno" à anarquia criativa que futuristas, dadaístas, cubistas e expressionistas já haviam exaltado no início do século XX, apresentamos um breve sumário da teoria psicanalítica de Julia Kristeva sobre a linguagem poética dos movimentos revolucionários de criação artística.

\section{ABSTRACT}

This paper deals with the dialectic process of creative revolution in art and design, according to a theory construed by psychoanalist Julia Kristeva in her doctoral thesis, published in France in 1974. Such theory seems to explain reasonably well the revolutionary work of those avant-garde artists and designers who have periodically tried to subvert the chief visual canons of their respective generations.

\section{PALAVRAS-CHAVE (KEY WORDS) \\ - Semiótica (Semiotics) \\ - Arte \& Design (Art \& Design) \\ - Criação (Creativity)}

\section{Flávio Vinicius Cauduro}

PhD Comunicação Gráfica, University of Reading, UK, 1990

\section{Introdução}

DePOIS DA TURBULÊNCIA das duas primeiras décadas do século $X X$, quando as propostas revolucionárias de futuristas, cubistas e dadaístas haviam instituído possibilidades radicalmente novas de significação visual, tradição mais tarde retomada por expressionistas e abstracionistas, o ímpeto renovador dos artistas plásticos foi arrefecendo, cedendo lugar à ordenação e à sistematização de suas descobertas iniciais.

Essa domesticação da criatividade anárquica também se fez sentir no design da comunicação gráfica, onde a influência da Bauhaus, uma escola subsidiada pelo Estado alemão, começou a ser cada vez maior, a partir da metade dos anos 20. A filosofia da Bauhaus incentivava o cultivo à ordem e ao racionalismo, visando à clareza e à harmonia, como se buscasse um contraponto visual ao conflito, à comoção, à anarquia, ao caos e à desestabilização do status quo, sentimentos que eram constantemente estimulados pelos movimentos sociais revolucionários na Europa, antes e principalmente depois da I Guerra Mundial.

A Escola Suíça que a sucedeu, após a II Guerra, refinou e reprimiu mais ainda quaisquer subjetivismos, improvisações ou expressionismos visuais que ameaçassem contaminar as formas gráficas idealizadas e propagadas pelas tendências racionalistas (tipos sem serifa, silhuetas pictográficas, cores primárias, diagramações geometrizantes). Seus designers maiores (Emil Ruder, Armin Hoffman, Josef MüllerBrockman) pregavam a superioridade universal de suas soluções minimalistas, rigidamente controladas pelo grid system e vestidas uniformemente pelas famílias Futura, Helvetica e Univers. Este estilo veio 
a ser conhecido durante o período dos anos 50 a 70 pela denominação de International Style, sendo adotado por quase todas as grandes empresas multinacionais, em seus programas de identidade visual corporativa, assim como por grandes editoras e por muitas escolas de design.

Essas soluções econômicas e contidas, que se justificavam pela ideologia do funcionalismo e do minimalismo (ornament is a crime, form follows function, less is more), eram repetidas incessantemente, tornandose em breve uma fórmula facilmente copiada por qualquer designer ocidental, independentemente de sua nacionalidade, cultura, talento ou preferências. As soluções gráficas ambicionavam tornarse formais, permanentes e universais, às custas da sensibilidade aos contextos comunicacionais.

Como era de esperar, as programações visuais que essas fórmulas mecanicistas geravam tornaram-se muito facilmente previsíveis e desinteressantes, passando a ser praticamente invisíveis após algum tempo. Isso era, na verdade, a conseqüência lógica e inevitável do seu princípio maior, o da funcionalidade: se a função de um determinado gênero gráfico era basicamente sempre a mesma, seguiase que não havia por que fazer maiores alterações nas formas já consagradas para aquele gênero - como, por exemplo, no caso de programas de sinalização visual, de programações visuais de impressos institucionais ou de criação de linhas de embalagens.

Essa monótona uniformização do design ocidental só vai começar a ser contestada a partir da segunda metade dos anos 60 , quando alguns jovens designers suíços (Odermatt \& Tissi em Zurique e Wolfgang Weingart, em Basle, entre outros) começam a propor alternativas nãodogmáticas, mais descontraídas (retorno à ornamentação, ao simbolismo, ao humor e à improvisação), para fugir da esterilidade das formas modernistas. Essa rejeição se espalha aos poucos pelas escolas norte-americanas, a partir dos anos 70, trazida por ex-alunos norte-americanos de Weingart (como April Greiman) que dão origem ao estilo expressionista/intuitivo da New Wave, que surge nos EUA e também ganha adeptos em países europeus, graças aos trabalhos, por exemplo, de Neville Brody, na Inglaterra, e Studio Dumbar, na Holanda.

O encontro desse espírito de rebeldia com as teorias desconstrucionistas produz os primeiros teóricos do design pós-moderno nos EUA, na Cranbrook Academy of Art, em Michigan, que a partir de 1978, sob a liderança de Katherine McCoy, começa a propagá-las através de posters e publicações (onde se destacam os de Scott Makella), e que confundem propositadamente a clássica distinção entre texto e ilustração, procurando produzir, por estratégias visuais sutis, uma leitura polissêmica dos traços impressos. Ao mesmo tempo, a grid é ignorada e o uso de elementos gráficos "inúteis", "ruidosos" e "anárquicos" é incentivado, visando ao enriquecimento das possibilidades expressivas e interpretativas tanto dos designers como dos leitores (vide Lupton \& Miller 1996: 7-9).

Atualmente, esse movimento de rejeição ao funcionalismo transformouse num leque de soluções bem típicas, reunidas sob a designação genérica de estilo pós-moderno (constituído pelas variantes techno, punk, grunge, pop)entre os designers gráficos. Ele se caracteriza pelo ecletismo de suas fontes históricas de inspiração (que incluem soluções vernaculares, regionais, como já há muito adotavam os designers do Push Pin Studio), pela valorização de elementos afetivos pessoais, pela introdução de impertinências visuais, pela hibridação das novas tecnologias da computação com mídias e técnicas mais tradicionais e pela procura de soluções aparentemente irracionais (trabalhadas em parte pelo acaso por fragmentos, deteriorações, defeitos, em 
parte por processos desconstrutivos das formas). Esses trabalhos são controlados pelo designer e realizados com a ajuda do, mas não só no, computador.

As influências que o design pósmoderno têm produzido até agora tem sido, de modo geral, visualmente estimulantes, inovadoras e provocantes, tendendo a liberar cada vez mais a criatividade artística dos designers, como muitos críticos têm enfatizado (Bielenberg 1994: 185, Livingston \& Livingston 1992: 159, Mills 1994: 130-1, Poynor 1994: 87).

Para tentar entender por que ocorreu mais essa revolução gráfica, que para os céticos conservadores, é simplesmente uma regressão irracional da estética visual do design contemporâneo àquela do início do século $\mathrm{XX}$, vamos lembrar aqui as teorizações psicanalítico-semióticas de Julia Kristeva sobre as inovações poéticas revolucionárias. Julgamos que o modelo proposto por Kristeva é de grande interesse para todos aqueles que procuram entender e estimular a criação, tanto no design como nas artes em geral, especialmente porque se preocupa em explicar comportamentos considerados aberrantes e transgressivos (e por isso mesmo desconsiderados) pelas teorias semióticas convencionais.

\section{A dialética da criação}

Segundo a psicoanalista e lingüista Julia Kristeva, toda criação artística de vanguarda é o resultado da manutenção da contradição no processo dialético de significação. Em sua tese de doutorado na França, posteriormente publicada em forma de livro, com o título de A Revolução da Linguagem Poética (Kristeva 1974/1984), ela afirma que Hegel havia identificado mas reprimira essa força biológica - a negatividade ou rejeição - que seria o quarto termo do processo dialético, aquele que impossibilitaria a permanência de qualquer síntese duradoura no trabalho de significação.
Segundo ela, a negatividade é um efeito das pulsões orgânicas semióticas que animam o sujeito desde o seu nascimento e que são reunidas numa chora (receptáculo) em seu corpo. Mesmo reprimida pelas estruturas familiares e sociais (da qual a linguagem faz parte), a partir da entrada do sujeito na fase edipal, essa força, recalcada no inconsciente, insiste constantemente em retornar e emergir na ordem simbólica, se manifestando por vários tipos de anomalias textuais (causadas pela chamada modalidade semiótica do sujeito, segundo ela).

A negatividade, a primazia e permanência da contradição, seria o resultado de impulsos arcaicos pré-edipais, desorganizados, tanto assimilativos como destrutivos, e que tornariam o corpo semiotizado "um lugar de permanente cisão" e relativa desordem (Kristeva 1974/ 1984: 27). Essa negatividade impediria a permanência de qualquer totalização harmônica e final na significação. Em troca, ela constituiria o sujeito "livre" (Kristeva 1974/1984: 112), o sujeito en procès (no duplo sentido de em processo/em julgamento), pois promoveria uma reorganização fundamental de suas posições de significação, que poderiam gerar por sua vez dissoluções produtivas, rupturas criativas, momentos de gozo, manifestações poéticas, mágicas, carnavalescas, assim como seria também responsável por psicoses, agressões, destruições, suicídios, pela loucura, enfim (Kristeva 1974/1984: 21-30).

Kristeva sumariza sua tese dizendo que existem

“... duas modalidades do que, para nós, é o mesmo processo de significação. A primeira chamaremos de 'semiótica', a segunda de 'simbólica'. Estas duas modalidades são inseparáveis no processo de significação que constitui a linguagem, e a dialética entre elas determina o tipo de discurso (narrativa, 
metalinguagem, teoria, poesia, etc.) envolvido; em outras palavras, a assim chamada linguagem 'natural' permite diferentes modos de articulação do semiótico e do simbólico. Por outro lado, existem sistemas de significação não-verbal que são construídos exclusivamente na base do semiótico (música, por exemplo). Mas, como veremos, esta exclusividade é relativa, precisamente devido à necessária dialética entre as duas modalidades do processo de significação que constitui o sujeito. Porque o sujeito é sempre tanto semiótico quanto simbólico, nenhum sistema de significação que ele produza pode ser ou 'exclusivamente' semiótico ou 'exclusivamente' simbólico, estando, ao contrário, necessariamente em dívida com ambos." (Kristeva 1974/ 1984: 23-24)

Baseada nas teorias psicoanalíticas de Freud e Lacan, Kristeva postulou que a linguagem funcionaria como uma escrita híbrida, hieroglífica, onde o analógico (ritmos, melodias, falhas e silêncios, contrações) seria regido pelo semiótico (o regime do afeto, da mãe) e o digital (os signos convencionais de uma língua ou de um código) pelo simbólico (o regime da lei, do pai), tanto nos sonhos como em atos conscientes de comunicação, e que a enunciação de mensagens, ao contrário do que se assume usualmente, não está sob o controle absoluto do consciente do sujeito (conforme assumem os cartesianistas).

Assim, ela enfatiza a importância da interpretação dos gestos paralingüísticos, das expressões faciais e das entonações na produção de sentido nas mensagens verbais, embora essas características tenham sido sistematicamente reprimidas pelas abordagens formais da linguagem. Aquelas assim chamadas "dimensões supra-segmentais" das mensagens verbais são tão importantes quanto as denotações que as acompanham, pois são governadas pelas emoções, pelo inconsciente, isto é, pelo corpo do sujeito, sendo sempre relevantes à interpretação contextualizada.

Portanto, de acordo com Kristeva, nas práticas comunicacionais temos uma signifiance, uma tessitura de significantes heterogêneos que intertextualiza discursos e textos históricos específicos para o sujeito. Estando necessariamente em contradição, uma vez que não existem ordens socioculturais vivendo em perfeita harmonia neste mundo, o trabalho de significação põe, portanto, o sujeito em processo/julgamento - ele vive o drama da dialética: instinto/razão, afeto/lei, analógico/ digital, pessoal/social, e assim por diante.

O sujeito está, por assim dizer, constantemente dividido entre seu ego consciente, racional, lógico, requerido pela vida em sociedade, e seu outro estado, subjetivo, inconsciente, corporal, que recolhe e combina estímulos afetiva e anarquicamente, sem respeitar categorizações e separações rígidas, formais, racionais, uma vez que segue a mobilidade dos impulsos associados aos significantes recebidos.

A permanência da negatividade no sujeito, portanto, torna impossível continuar concebendo o sujeito como um indivíduo, como um ser uno, cartesiano, nãodivisível, lógico, racional, sempre em total controle de seus atos, como concebido tradicionalmente por filósofos e psicólogos humanistas.

Conseqüentemente, afirma Kristeva,

"a negatividade hegeliana previne a imobilização do tético, desloca a doxa, e abre caminho para toda a motilidade semiótica que a prepara e excede. Hegel... define esta negativi-dade como o quarto termo da verdadeira dialética: triplicidade [tese-antítesesíntese] é apenas uma aparência no campo do entendimento" (Kristeva 1974/1984: 113).

Ou seja, segundo Kristeva, todas as 
sínteses são estases temporárias, nada permanece, tudo muda. $\mathrm{E}$, ao contrário do que idealizam a maioria dos filósofos, o que prevalece nos sujeitos e nos eventos é heterogeneidade, pluralidade, mudança, fragmentação, complexidade, rupturas.

Por isso, enfatiza Kristeva, a linguagem não é simplesmente um código, um jogo intelectual, mas sim uma praxis, uma prática significante, um trabalho incessante de interpretação da realidade, uma produção - que necessita e envolve um sujeito concreto, material, dividido entre duas modalidades de significação, a semiótica, da ordem dos impulsos, e a simbólica, da ordem dos símbolos (signos convencionais), modalidades essas que substituem as ordens imaginária e simbólica, ambas masculinas, do sujeito lacaniano (Moi, in Kristeva 1986: 12).

Como observa o crítico literário inglês Terry Eagleton:

"O [regime] semiótico põe em confusão todas as rígidas divisões entre masculino e feminino - é uma forma bissexual de escrita - e se propõe a desconstruir todas as escrupulosas oposições binárias - próprio/impróprio, norma/desvio, são/louco, meu/teu, autoridade/ obediência - pelas quais sociedades como a nossa sobrevivem." (Eagleton 1983: 189)

Toril Moi, uma das seguidoras de Kristeva, coloca por sua vez:

“... signifiance é uma questão de posicionamento. O contínuo semiótico deve ser dividido para se produzir a significação. Esse corte (coupure) do chora semiótico é a fase tética (de tese), que permite ao sujeito atribuir diferenças e assim significação àquilo que era a heterogeneidade incessante do chora. Seguindo Lacan, Kristeva coloca a fase do espelho como o primeiro passo que permite 'a constituição de objetos separados do chora semió-tico'..., e a fase edipal, com sua ameaça de castração, como o momento em que o processo de separação ou divisão é integralmente completado [e o sujeito aceita definitivamente $o$ signo no lugar do objeto]. Uma vez que o sujeito tenha entrado na ordem simbólica, o chora será reprimido com maior ou menor sucesso e poderá ser apenas percebido como uma pressão pulsional sobre ou dentro da linguagem simbólica: como contradições, nonsense, distúrbios, silêncios e ausências. O chora, portanto, é uma pulsão rítmica e não uma nova linguagem. Ele constitui a dimensão heterogênea, anárquica, da linguagem, aquilo que nunca poderá ser encerrado nos fechamentos da teoria lingüística tradicional." (Moi, in Kristeva 1986: 13)

Para Kristeva, arte em geral, e literatura avant-garde em particular, é o lugar privilegiado para a ocorrência de rejeições e a observação de exemplos concretos de inovações criativas e intrusivas por elas motivadas. É óbvio que podemos extrapolar a ação da negatividade para outros campos de atividade humana, como a prática do design da comunicação gráfica, por exemplo, assim como identificar resultados muitas vezes assustadores para a ordem constituída (surtos, loucuras, atos desesperados ou violentos, etc.).

Segundo Kristeva, o desejo lacaniano nada mais seria que um disfarce semântico para aquela mesma negatividade ou rejeição da dialética hegeliana, podendo também ser reconhecida no instinto de morte que tanto intrigava Freud por sua irracionalidade (Kristeva 1974/1984:130131).

Por isso, diz ela, o desejo lacaniano

"não pode explicar completamente os mecanismos do processo de 
significação. Na tecnologia e na política, mas também na arte, tem-se encontrado áreas nas quais o desejo é excedido por um movimento que sobrepassa as stases da estrutura do desejo e desloca os referenciais dos dispositivos inter-subjetivos onde identificações fantas-máticas congelam" (Kristeva 1974/1984: 146).

A rejeição ou negatividade dissolve posições tradicionais de significação, produzindo jouissance, ou prazer sublime, na medida em que o sujeito rompe com antigas posições téticas e esquemas de significação prescritos pelo social - seja através de dispositivos poéticos, desvios sintáticos, transgressões simbólicas, irracionalidades, absurdos, etc., que terminam por causar mudanças radicais, muitas vezes revolucionárias, na linguagem, nas estruturas da família, na política, na educação, nas artes, e assim por diante. Isto se deve ao fato de que, como ela coloca, as práticas significantes inspiradas pela rejeição redistribuem assimetrias afetivas e de poder, assim como renovam a ordem simbólica:

"O que entendemos por rejeição é precisamente o modo semiótico de ... uma permanente agressividade e a possibilidade dela ser afirmarda e, portanto, de ser renovada. Embora seja destrutiva - um 'impulso de morte' -, a rejeição é o verdadeiro mecanismo da reativação, da tensão, da vida; objetivando a equalização da tensão, se dirigindo para um estado de inércia e morte, ela perpetua a tensão e a vida." (Kristeva 1974/1984: 150)

“... a rejeição re-constitui objetos reais, 'cria' novos, reinventa o real e o re-simboliza. Embora ao fazê-lo a rejeição lembre um processo regressivo esquizóide, é mais importante observar que a rejeição positiviza aquele processo, afirmando-o, ao introduzir aquele processo na esfera do significar: este último [o significar] portanto se descobre separado, dividido, posto em processo/julgamento [da mesma maneira que o sujeito]." (Kristeva 1974/1984: 155)

A rejeição não pode ser ignorada nem sufocada, pois ela atua com a regularidade das leis objetivas, como pulsações regulares produzindo novos arranjos do simbólico. Ao mesmo tempo, a rejeição traz mudanças, liberdade, riso, prazer e produtividade às praticas da significação. Como Kristeva observa, a rejeição estimula o redirecionamento do desejo de cada sujeito, pois:

"A lógica da rejeição não apenas precede ... o escorregar metonímico do desejo [lacaniano], mas é a base e talvez mesmo a fonte inspiradora de uma prática que envolve o gozar e a transformação do significar da realidade social imediata. ... O sujeito de tal prática investe desejo e fantasia mais em sua produtividade do que em suas produções; mas uma vez que as produções são parte da transformação do real, o sujeito investe o desejo na transformação de si mesmo." (Kristeva 1974/1984: 178, ênfase minha).

O que Kristeva enfatiza, portanto, é que não existe possibilidade de criar qualquer coisa realmente nova, excitante, radical, se o sujeito continuar aceitando o compromisso da dialética hegeliana, a síntese acomodativa (Kristeva 1986: 59). O senso comum reprime o novo sentido, a tradição inibe a experimentação, a repetição paralisa a inovação, definições previnem trans-formações, a continuidade desestimula a ruptura. Para que haja criação e inovação, o sujeito significante tem que poder alternar momentos de afirmação com momentos de rejeição, de 
aceitação com negação, de repetição com experimentação.

Assim, o sujeito da significação, que Lacan contempla como um sujeito conformado, passivo, impotente, desejante, deve ser reconsiderado, pois este é um posicionamento que visa a acomodar o sujeito ao status quo, à ordem simbólica falogocêntrica vigente, como diz Derrida, seja em que campo for. $O$ objetivo final de uma prática significante realmente criativa deve ser não simplesmente "curar" e "adaptar" o sujeito à sua formação sociocultural, mas transformar situações opressivas, repressivas, repetitivas, em oportunidades para experimentar, intervir, mudar, inovar, provocar, liberando a prática criadora/transformadora da negatividade.

E, como Kristeva observa, "toda prática que produz algo novo (um novo dispositivo) é uma prática de rir: ela obedece à lógica do riso e provê o sujeito com as vantagens do riso. Quando a prática não produz riso, nada existe de novo; onde nada é novo, a prática não pode ser provocante: na melhor das hipóteses, é um ato repetitivo, vazio" (Kristeva 1974/1984: 225).

O processo dialético de significação, que coloca o sujeito en procés, segundo Kristeva, impede a manutenção de posições fixas de predicação. Isso se deve aos processos primários do inconsciente, de deslocamentos e condensações, e à intertextualização - transposição de signos de um sistema para outro (Kristeva 1986: 110-11). Por isso, ela observa, polissemia e contradições são inerentes e intrínsecas à significação (Kristeva 1986: 111).

Assim, podemos dizer que o sujeito da significação é um signo em permanente semiose, de acordo com Peirce. Ou, segundo Lacan, que ele/ela é também uma encruzilhada, um carrefour de sentidos, um nó, um ponto de encontro de significantes, ou o centro de uma constelação de significados, segundo Saussure. Mas sempre heterogêneos, muitas vezes contraditórios.

\section{Portanto, ocorre que}

“... o momento da prática dissolve a compactação do sujeito e sua autopresença ... ele coloca o sujeito em contato com, e portanto numa posição de negar, vários objetos e outros sujeitos do seu meio social, com o qual o sujeito entra em contradição.... Essa contradição ... de-centra e suspende o sujeito, articulando-o como um corredor de passagem, um não-lugar, onde ocorre uma luta entre tendências conflitantes, impulsos cujas estases e momentos téticos (o representamen) estão tão arraigados em relações afetivas (familiares e amorosas) como em conflitos de classe. No momento de rejeição ... um componente unificador, simbólico, ideológico, e portanto positivo, intervém ... de maneira a constituir, dentro da linguagem, o novo objeto produzido pelo sujeito em processo/ julgamento através do processo de rejeição. O momento fundamental da prática é, portanto, a contradição heterogênea que posiciona um sujeito em processo/julgamento por um exterior natural ou social ainda não simbolizado, um sujeito em conflito com teses prévias (em outras palavras, com aqueles sistemas de representação que deferem e adiam a violência da rejeição)." (Kristeva 1974/ 1984: 203)

Ou seja, a prática da significação só pode produzir o novo através da pulverização da unidade da consciência do sujeito, ao fazê-lo prestar atenção ao exterior não simbolizado e contraditório, às falhas e descontinuidades que desafiam interpretações usuais (classificações, definições, taxonomias). É nesses momentos que o processo de significação, enquanto um processo de julgamento de posições téticas, realmente ocorre em toda a sua potencialidade. 
Esses são momentos de angústia, terror, ambigüidades, paradoxos, rupturas, que dissolvem a aparente unidade e estabilidade do sujeito, "apenas para recolocá-lo novamente, renovado" (Kristeva 1974/1984: 204). É exatamente aí, quando a realidade se torna opaca, estranha, heterogênea, que somos convocados pela razão a torná-la novamente natural, harmoniosa, coerente com nossas crenças básicas, mas informadas por novas posições de significação. É o assim chamado "momento da verdade" para o sujeito, o momento em que ocorre uma nova luta pela produção do sentido. É exatamente aí que ocorre a oportunidade de criar algo novo. É nessas ocasiões também que nos damos conta que estamos constantemente sujeitos a verdades gastas e obsoletas, à "sistemas inteiros de mitos e preconceitos que nos posicionam socialmente de uma maneira específica e governam nossa visão da sociedade.... [Uma sujeição inconsciente que] inclui todas aquelas coisas que consideramos como dadas, que não questionamos porque assumimos que são verdadeiras - não nos dando conta que em vez de verdades, são construções elaboradas que servem aos interesses de grupos, classes ou partidos [falogocêntricos] no poder" (Roudiez, in Kristeva 1974/1984: 8).

Segundo Kristeva, o sujeito do desejo não está simplesmente à procura de consumo passivo, ou produtos atraentes, objetos metonímicos de desejo; ao contrário, o sujeito está submetido constantemente a contradições em suas predicações, renovando constantemente as identificações narcisísticas de seu ego (Kristeva 1974/1984: 186).

Ou seja, o sujeito oscila constantemente entre afirmação e contradição, até que uma nova tese significante seja produzida, com a conseqüente rejeição de antigas posições de predicação. Assim, “... a rejeição ... desmantela o representamen e, a partir da heterogeneidade da prática ou experiência da rejeição, ... produz novas simbolizações.
Este é o mecanismo da inovação que desloca o referencial do real ..." (Kristeva 1974/1984: 179)

Ela argumenta, em prosseguimento, que textos que são usualmente considerados poéticos, revolucionários, radicais, sejam literários ou não, têm uma função ética, aqui entendida sob uma nova perspectiva, que é aquela da negativização das fixações narcisísticas, dentro de uma prática que pluraliza, pulveriza e provoca as verdades recebidas, de maneira a poder romper com posições idealistas de significação, incapazes de especificar relações materiais por estarem comprometidas com interesses socioeconômicos específicos (Kristeva 1974/1984: 233).

Assim, ao contrário das filosofias que procuram explicar o mundo, o processo de significação poético enfatizado por Kristeva, e baseado na dialética, quer, ao contrário, mudá-lo, falando para um novo sujeito que, como o antigo, também explica, cogita e conhece o mundo, mas que, por outro lado, não se deixa capturar pelo mesmo, porque está sempre procurando transformar o real. Ao explicar, cogitar e conhecer, ele enfatiza um pólo da contradição heterogênea sobre o outro, enfatiza processo em vez da identificação, rejeição em vez do desejo, heterogeneidade em vez do significante, luta em vez de estrutura (Kristeva 1974/ 1984: 178-179).

Como pode se observar, o processo de significação proposto por Kristeva está fundamentado numa dialética de renovação de teses, que reintroduz na arena da semiose todos aqueles aspectos incômodos, anárquicos, irracionais e verdadeiramente criativos que a lógica formal, a lingüística tradicional e o estruturalismo rígido procuravam sistematicamente ignorar ou reprimir. Kristeva, ao contrário, enfatiza justamente a dimensão poética, transgressiva, renovadora da significação, que não é aceita pelo discurso da ciência burocrática: 
"O discurso científico, ... ao aspirar ao status de uma metalinguagem, tende a reduzir o máximo possível o componente semiótico ... É a linguagem poética que desperta nossa atenção para ... o caráter indecidível de qualquer uma das assim chamadas linguagens naturais, uma característica que o discurso unívoco, racional, científico tende a esconder" (Kristeva 1980/1977: 134-135). Ela admite que "o domínio transcendental sobre o discurso é possível, mas é repressivo: tal posição é necessária, mas apenas como um limite aberto a constantes desafios" (Kristeva 1977/ 1980: 140).

Como acrescenta Terry Eagleton, a modalidade semiótica é reprimida pelo establishment científico, racional e liberal porque ela afeta o significante público, o representamen, ao invés do significado privado, o conceito, o sentido particular das representações, o objeto secreto de nossos desejos. $E$ é isso que é visto como perigoso pelos grupos conservadores, uma vez que inovações no campo dos significantes costumam desafiar a ordem constituída, a hegemonia e autoridade de certos textos - políticos, religiosos e sociais - que incentivam o consumismo, a acomodação, a preservação dos cânones e a obediência a situações de passividade engendradas pelo status quo. Como ele diz, no contexto da teoria literária:

"Ninguém está especialmente
preocupado com o que você diz,
que posição - moderada, radical ou
conservadora - você adota, desde
que seja compatível com, e possa
ser articulada dentro de uma forma
específica de discurso. Ocorre,
entretanto, que certos sentidos e
posições deixarão de ser articulados
[por não se ajustarem a essas formas
tradicionais] ....

... A crítica literária seleciona, processa, corrige e reescreve textos de acordo com certas normas institucionali-zadas do que seja 'literário'... Existem certamente muitas maneiras notáveis de falar acerca de literatura que ela exclui, assim como muitos movimentos e estratégias notáveis que ela desqualifica como inválidos, ilícitos, absurdos. A sua aparente generosidade no plano do significado é justamente contraposta pela sua sectária intolerância no nível do significante. Dialetos regionais do discurso, por assim dizer, são reconhecidos e algumas vezes tolerados, mas você não deve dar a impressão de estar falando uma outra língua completamente diferente." (Eagleton 1983: 201, 203)

Como observamos, as considerações de Kristeva e Eagleton são extremamente pertinentes para a explicação de práticas poéticas radicais ou transgressivas, como a prática criativa do design gráfico que subverte os cânones vigentes, rejeitando os representamens oficiais, seja qual for a época, estilo ou movimento considerado, para inovar. Também podem explicar porque muitos designers se alinham com o seu oposto, com a prática tradicional, conservadora, e muito cômoda, da neutralidade e invisibilidade da escrita gráfica, a serviço da "retórica do logocentrismo" (Cauduro, 1998), ou simplesmente reprodutoras de formas burocráticas e banais.

Criatividade pressupõe, portanto,transgressão de normas socialmente aceitas e de modos de pensar do bom-senso. Pois criar é desviar-se de certas regras, leis e convenções sociais e de seus símbolos mais representativos, em busca de novas configurações semióticas e novas possibilidades de significação. Só assim o novo, o inédito, pode aparecer e renovar uma vez mais o social.

Como bem sintetiza um antigo ditado, 
"aquele que segue a multidão nunca irá além dela. Mas aquele que caminha sòzinho muito provavelmente descobrirá lugares onde ninguém esteve antes". Lugares novos que serão, mais cedo ou mais tarde, inevitavelmente de domínio público .

\section{Referências}

BIELENBERG, John (1997) 'Thinking About Communication', in Looking Closer 2: Critical Writing on Graphic Design, ed, por Michael Bierut e outros, New York: Allworth Press and American Institute of Graphic Arts, 1997, pp. 183-185.

CAUDURO, Flávio Vinicius (1998) 'A retórica tipográfica do logocentrismo', in Anais do P\&D 98 - III Congresso Brasileiro de Pesquisa e Desenvolvimento em Design - 25 a 28 de outubro de 1998, Rio de Janeiro, vol 2, editado por Anamaria de Moraes e Alfredo Jefferson de Oliveira, Rio de Janeiro: Associação de Ensino de Design do Brasil/Revista Estudos em Design, pp. 604-611.

EAGLETON, Terry (1983) Literary Theory: An Introduction, Oxford: Basil Blackwell

KRISTEVA, Julia (1969/1981) Le langage, cet inconnu, Points, Paris: Éditions du Seuil

KRISTEVA, Julia (1974/1984) Revolution in Poetic Language, traduzido por Margaret Waller com uma introdução de Leon S Roudiez, New York: Columbia University Press (First published in 1974 as La révolution du langage poétique, Paris: Éditions du Seuil).

KRISTEVA, Julia (1977/1980) Desire in Language: A Semiotic Approach to Literature and Art, ed. por Leon S Roudiez e traduzido por T Gora, A Jardine, and L Roudiez, Oxford: Basil Blackwell (First published in 1977 as Polylogue, Paris: Éditions du Seuil).

KRISTEVA, Julia (1981) 'The Semiotic Activity', in Screen Reader 2: Cinema \& Semiotics, London: The Society for Education in Film and Television.

KRISTEVA, Julia (1986) The Kristeva Reader, editado e com uma por Toril Moi, London: Basil Blackwell.
LIVINGSTON, Alan, \& LIVINGSTON, Isabella (1992) The Thames and Hudson Encyclopaedia of Graphic Design and Designers, London: Thames \& Hudson.

LUPTON, Ellen, \& MLLLER, J. Abbott (1996) Design Writing Research: Writing on Graphic Design, New York: Princeton Architectural Press.

MILLS, Mike (1994) 'The (Layered) Vision Thing', in Looking Closer: Critical Writing on Graphic Design, ed, por Michael Bierut e outros, New York: Allworth Press and American Institute of Graphic Arts, 1994, pp. 129-131.

POYNOR, Rick (1994) 'Type and Deconstruction in the Digital Era', in Looking Closer: Critical Writing on Graphic Design, ed, por Michael Bierut e outros, New York: Allworth Press and American Institute of Graphic Arts, 1994, pp. 83-87. 